\title{
Non-native writers and the use of appraisal resources in research article introductions
}

\author{
Sri Wuli Fitriati and Yuni Awalaturrohmah Solihah
}

\author{
Gedung B3 dan B8 Kampus Sekaran, Jalan Raya Sekaran Gunungpati, Semarang 50229, Central Java, Indonesia
}

\begin{tabular}{|c|c|}
\hline $\begin{array}{l}\text { ABSTRACT } \\
\text { Writing an introduction section of a research article usua } \\
\text { arguments for building up a sense of persuasiveness tha } \\
\text { article introduction can be achieved by using appraisal } \\
\text { and propositions effectively. Using twenty introduction } \\
\text { English by Indonesian and Chinese writers as non-native } \\
\text { appraisal resources and compares their distributions. By } \\
\text { Appraisal resources theory drawn from the work of } \\
\text { reveal that there are both similarities and differences in } \\
\text { between Indonesian and Chinese writers in the introd } \\
\text { terms of similarities, both Indonesian and Chinese writ } \\
\text { (engagement), and force (graduation) as the most used an } \\
\text { is different, however, is that the Indonesian writers seem } \\
\text { appraisal resources overall, except for graduation resour } \\
\text { Chinese writers. This article discusses some of the peda } \\
\text { teaching students of English as a foreign language and } \\
\text { voice and arguments in the writing of research article int }\end{array}$ & $\begin{array}{l}\text { uires the interpersonal voice and } \\
\text { entice readers. A quality research } \\
\text { es to represent the writers' ideas } \\
\text { ns of research articles written in } \\
\text { ss, this study examines the use of } \\
\text { oying textual analysis and using } \\
\text { and White (2005), the findings } \\
\text { istribution of appraisal resources } \\
\text { sections of research articles. In } \\
\text { e attitude (appreciation), expand } \\
\text { l resources in their writing. What } \\
\text { likely than Chinese writers to use } \\
\text { aich were used more often by the } \\
\text { l implications for those who are } \\
\text { to improve and strengthen their } \\
\text { ons. }\end{array}$ \\
\hline $\begin{array}{l}\text { Keywords: appraisal resources; research article introduc } \\
\text { analysis }\end{array}$ & non-native writers; discourse \\
\hline $\begin{array}{l}\text { First Received: } \\
28 \text { Maret } 2018 \\
\text { Final Proof Received: } \\
\text { 25 January } 2019\end{array}$ & $\begin{array}{c}\text { Accepted: } \\
\text { 30 November } 2018 \\
\text { Published: } \\
\text { 31 January 2019 }\end{array}$ \\
\hline $\begin{array}{l}\text { How to cite (in APA style): } \\
\text { Fitriati, S. W. \& Solihah, Y. A. (2019). Non-native writ } \\
\text { research article introductions. Indonesian Journal } \\
\text { doi: } 10.17509 / \text { ijal.v8i3.15265 }\end{array}$ & $\begin{array}{l}\text { the use of appraisal resources in } \\
\text { ied Linguistics, } 8,638-645 \text {. }\end{array}$ \\
\hline
\end{tabular}

\section{INTRODUCTION}

Writing scientific papers such as research articles is an important skill for advanced learners of English as a Second Language (ESL) or English as a Foreign Language (EFL). As a process-oriented, the English language learners might attempt to create good academic writing through their language use. Yuliana and Gandana (2018) argue that to make a good piece of academic writing, writers "present a clear position and show engagement with a range of ideas to support it" ( $p$. 613). This is in line with Jalilifar and Hemmati (2013), who suggest that the interaction between a writer and potential readers can be achieved through the interpersonal meanings of the text, by employing sound arguments so that the readers are persuaded. Academic writing provides writers with a means to utilize their ideas and opinions and therefore intrigue readers' mind.

In academic contexts, creating academic writing is a crucial issue for many scholars, especially in relation to writing research-based articles (henceforth, research articles). Scholars explore certain topics which are investigated as part of their studies, in order that those reading their work will understand the significance and know the results of their research. According to Hyland (2009), "a research article is a widely researched area for English for Academic Purposes (EAP), and it

\footnotetext{
* Corresponding Author

Email: SriWuli.Fitriati@mail.unnes.ac.id
} 
continues to be the pre-eminent genre of the academy and is the principal site of knowledge-making" (p. 67). This highlights that research articles are important as they give models for English language learners to use for writing scientific papers and they are sources of knowledge dissemination in particular fields. Moreover, a research article involves the writers' personal voice towards the topic explored and this is needed for helping readers to enrich their knowledge.

A research article consists of several parts, including an introduction section which is one of the important parts to help readers figure out the interest of the writers, and the importance, significance, and background of the topic (Hyland, 2005, 2009). Hood (2004) asserts that in writing an introduction to a research paper writers need to persuade readers that their research has some significance, that there is space for new knowledge around the topic, and that they can make a contribution to knowledge. Therefore, an introduction section is the main part of the research article to introduce why the writer has investigated the topic. It is also the first viewpoint for readers to know the problems of the topic that will be answered in the sections of the research articles. In other words, by reading the introduction section, readers can infer the reasons why the writer takes the topic to be investigated.

As a result, writers need to build interaction between their writing and readers (Thornbury, 2005). One way to establish such interaction and make the interpersonal meaning of language more effective is the use of appraisal resources (Hyland, 2005; Martin \& Rose, 2003; Martin \& White, 2005). Appraisal theory helps to explain how writers or speakers use language to construct their relationship with readers and listeners (Hyland, 2005; Martin \& White, 2005). This theory can help us to analyse how writers' voices and ideas are conveyed through the choice of words in their writing or speaking. According to Hyland (2005), appraisal theory offers a systematic tool which can be used to analyse language as it offers a typology of evaluative resources. Through appraisal resources, English language users can create different varieties of meaning-making.

Appraisal resources were developed from the interpersonal metafunction in the framework of Systemic Functional Linguistics (SFL). The resources provide a framework for analysing the evaluation of language and discovering meaning in the context where it is used. White (2015) states that, to negotiate meaning, utterances produced by a speaker or clauses produced by a writer show the speaker's or writer's personal evaluation towards phenomena, thus sharing his/her position, whether it is positive or negative. According to Martin and Rose (2003), appraisal resources negotiate the social relationship between the speaker/writer and listener/reader. As Martin and White (2005) state, the theory of appraisal proposes a taxonomy that consists of three domains: attitude, engagement, and graduation resources. Attitude is concerned with feelings, including emotional reactions, judgments of behavior, and evaluation of phenomena.
Engagement deals with sourcing attitudes and the play of voices around opinions in discourse. Graduation attends to grading phenomena, whereby feelings are amplified and categories blurred (Martin \& White, 2005 , p. 35). Thus the resources allow the exploration of interpersonal meaning at semantic discourse level and the analysis of the writer's positioning of the phenomena within a particular context.

Research on this evaluative language known as appraisal resources has been carried out in a range of academic contexts with different purposes, focuses, and scholars. Some researchers are predominantly interested in investigating the use of appraisal resources in academic writing, especially students' argumentative essays (e.g., Jalilifar \& Hemmati, 2013; Liu 2013; Mei \& Allison, 2003; Xinghua \& Thompson, 2009; Yang, 2016). For example, Yuliana and Gandana (2018) conducted a study of engagement analysis to examine how Indonesian university students construct their voice in analytical, expository texts. They considered three categories of students - those with results above average, average, and below average - to examine to what extent they produce engagement resources to support their voices in their texts. The results show that the above average students are successful in constructing a well-argued text and showing a stronger sense of authority. This study also gives consideration to developing students' voice in writing by using engagement resources, especially for EFL learners.

Another appraisal study of academic papers was carried out by Saptani (2017) who compared how male and female undergraduate students produce appraisal resources in the introduction section of writing about their final projects. She analysed all resources of appraisal: attitude, engagement, and graduation. The results show that there are three similarities and three differences between the writing of male and female students and in relation to the most and the least favourable kinds of attitude, what were appraised, and the variety of attitude resources. In terms of engagement resources, there are two similarities regarding the types of engagement used and no differences. In terms of graduation system, two similarities and a difference were identified. The similarities were in relation to force, as the most favored type of graduation, whereas the difference was regarding the use of focus in male students' introductions.

Furthermore, Yang (2016) investigated the appraisal resources used by Chinese and American writers in English argumentative essays. The results show that overall use of appraisal resources in American writing is better structured than Chinese writing. In relation to attitude, the Chinese and American writers produced more appreciation than judgement and affect. With engagement, the Chinese writers used more of the contract subsystem in the form of disclaim and proclaim, while the American writers used more expand subsystem including entertain and attribute. In relation to graduation, the Chinese and American writers produced more force than focus. 
Previous studies on evaluation in language use have shown rapid development in the educational field of English as a foreign language. However, there are few studies that explore the use of evaluative language in scholars' writing, especially research articles. The research article is one type of academic writing that can be investigated, due to the fact that it involves the dissemination of knowledge-meaning for readers. As a result, it is of empirical interest to discover the intention of writers of the research article itself. Over the years, scholars have published their research articles so that they can be accessed by readers. According to Yang (2016), "in the field of second language learning, Chinese researchers paid more and more interests in second language writing" (p. 1002). Numerous Chinese researchers contribute their writing in second language learning studies and readers can easily find their studies in scientific research journals.

Similarly, many Indonesian writers also write research articles that are published in conference proceedings and academic journals. Proceedings and journals are the places for Indonesian scholars/writers to show their academic writing skills and their research abilities and findings. As non-native writers of English, like Indonesian and Chinese writers, writing research articles is a good opportunity to develop and enhance competence in writing. Hyland (2003) as cited in Yang (2016) states that "second language writing is not only a great challenge in the second language but also a hot research topic" (p. 1002). Farnia and Barati (2017) argue that "numerous studies have examined how different research article sections in diverse disciplines are written using genre-based approach" (p. 486). Indeed, investigating research articles has been a growing trend for years. However, studies on research articles with the focus on the appraisal resources used by non-English native speakers have been relatively limited.

The study described in this article investigates language use in research articles produced by Indonesian and Chinese writers, who are non-native speakers of English. The choice of Indonesian and Chinese writers was based on the practical reason that in China, as well as in Indonesia, the English language is a foreign language (Rao, 2013). The particular focus of the research was the use of appraisal resources.

Unlike previous studies which compared the use of appraisal resources in native and non-native students' argumentative writing (e.g., Saptani, 2017; Yang, 2016), this study investigates appraisal resources in non-native writers' research article introductions. As far as the researchers are aware, investigation of the use of appraisal resources in the introduction sections of research articles produced by Indonesian and Chinese writers has not been previously conducted.

The current investigation explores the interpersonal meaning resources that are used, to analyse how the intention of writers in conveying their attitudes, opinions, or ideas is evident in their choice of words. In particular, the aim is to examine the similarities and differences in the use of appraisal resources in the introduction section of Indonesian and Chinese writers' research articles.

\section{METHOD}

To achieve the study's aim, the researchers used discourse analysis of written text as a research approach. Discourse analysis is defined as an attempt to study the organization of language above the sentence or clause, and therefore to study larger linguistic units, such as conversational exchanges or written text (Stubbs, 1983; Widdowson, 2004).

The researchers collected a total of 20 research articles: 10 research articles written by Indonesian writers and 10 written by Chinese writers. The 10 examples from Indonesian writers came from "The $6^{\text {th }}$ ELTLT Conference Proceedings 2017', and the 10 research articles by Chinese writers were taken from a selection of journals including the Electronic Journal of Foreign Language Teaching, Journal of Language Teaching and Research, Issues in Language Teaching, Prospect, and Canadian Social Science. We acknowledge that the review process of the published articles in proceedings and journals might be slightly different. Generally, the review process for journals is stricter than that for conference proceedings. However, we employed a purposeful sampling technique. This means that the articles in this present study had to be research-based articles in the field of English language teaching, and of approximately the same length. In addition, the articles from the proceedings derived from an international conference with some reviewers from foreign countries, so the appropriateness of the sources of data in this study could be achieved. The authors' bionotes were used to identify the authors' country.

The framework of appraisal resources used for the analysis of writing was drawn from Martin and White's theory (2005). As Chatterjee (2008) explains, the appraisal taxonomy can be used to make sense of the lexical and grammatical choices made by writers. This type of analysis enables researchers to examine texts that authors have written and to infer the decisions made by those writers as they constructed their introductions to research papers.

The 10 introductions were analysed in relation to the three domains: attitude, engagement, and graduation. Words, phrases, and clauses were identified as appraising items. The procedures of the analysis were: (1) classifying the appraising items in the introduction section of research articles; (2) quantifying the use of appraisal resources in the form of a table; (3) discovering the similarities and differences between Indonesian and Chinese writers in using the appraisal resources.

\section{FINDINGS AND DISCUSSION}

The findings revealed some similarities and differences in the use of appraisal resources in Indonesian and Chinese writers' introduction sections of research 
articles. It is important to note, however, that this study analysed only a small number of writing samples. Although there is much to learn from the analysis, it is important to remember that the findings cannot be generalised to explain all examples of writing from all Indonesian and Chinese scholars. Rather, the findings open up for discussion the use of appraisal resources and possible interpretation of what their use might mean for those teaching English as a second or foreign language. In the discussion below, the scholars' writing is quoted verbatim. As a result, some errors in language usage and grammar are evident.

\section{Similarities in the use of appraisal resources}

In terms of similarities in the use of appraisal, the Indonesian and Chinese writers have a high occurrence in all subsystems of appraisal resources, namely attitude (appreciation), engagement (expand), and graduation (force).

The first subsystem of appraisal resources is attitude. Attitude is the main resource in Appraisal theory that explains speaker/writer's feelings, emotions, and judgement toward something in conveying meaning/information during the interaction (Martin \& Rose 2003; Martin \& White 2005). It relates to the language user's emotions or feelings to judge or appreciate things in the context. It is divided into three resources, namely: expressing feelings/emotion as affect resources, expressing for judging character/human behaviour as judgment resources, and expressing the value of things as appreciation resources (Martin \& Rose 2003; Martin \& White 2005). In line with White (2015), attitudinal meaning concerns positive and negative assessment that relies on three broad domains of attitude, such as affect, judgment, and appreciation as subsystems of attitude resources.

The analysis shows that in terms of the attitude subsystem, appreciation is used by both Indonesian and Chinese writers. This finding is in line with the studies by Lee (2006), Xinghua and Thompson (2009), Liu and Thompson (2009), Liu (2013), and Jalilifar and Hemmati (2013). It indicates that the Indonesian and Chinese writers appreciate and evaluate things or phenomena as their certain topics in the introduction section of research articles. It also reveals that they use the introduction section of research articles to explain and describe things that are related to their topics. Some examples of appreciation resources that are found in the Indonesian and Chinese writers' introductions are provided in Excerpt 1 and Excerpt 2 respectively.

\section{Excerpt 1:}

Advertising plays an important[APPRECIATION] role marketing and sales of a product.

Television as a medium of mass communication has a big[APPRECIATION] role in disseminating information and providing entertainment to all levels of society.

Television as a media of communication has the power of persuasive[APPRECIATION] information since it is able to generate strong[APPRECIATION] influence by emphasizing the two senses at the same time, namely hearing and sight (I2)
Excerpt 2

J. R. Martin has put forward a new [APPRECIATION] angle for discourse analysis, that is, positive discourse analysis (PDA) and appraisal theory serves as its theoretical(APPRECIATION) basis.

PDA has gained great[APPRECIATION] interest from scholars at home and abroad. However, there are few research studying Chinese leaders' speech nowadays (C4)

As can be seen in Excerpts 1 and 2, the appraising items of 'important,' 'big,' 'persuasive,' 'strong,' 'new,' 'theoretical,' 'great,' and 'major' are examples of appreciation resources. Those words represent the writers' evaluations of the phenomena, and in this case, the words evaluate phenomena relating to the topics that are discussed in the introduction section of research articles.

In Excerpt 1, the appraising item 'important' evaluates advertising as the Indonesian writers' topic. The writer conveys his appreciation of the value of advertising. This appreciation/evaluation presents the writer's view of the importance of advertising in the marketing and sales of a product. Moreover, in the second sentence, the appraising item 'big' evaluates the role of television in sharing information to society. It is also shown in the appraising item 'persuasive' that the writer seems to be evaluating the power of television as a medium of communication. For the appraising item 'strong,' the writer examines the influence of television due to the powerful persuasion that it can engender. All appraising items in Excerpt 1 examine the evaluation of things or phenomena, especially the role of advertising and television, as a way of introducing the topic in the introduction section of the research article.

In Excerpt 2, the writer describes 'new' as the appraising item to evaluate the innovation which is formed by J. R. Martin about a field of discourse analysis. The appraising item 'theoretical' provides a way of explaining and justifying the authenticity of positive discourse analysis and appraisal theory. The other appraising item 'great' evaluates the popularity of positive discourse analysis in the research area. The topics of positive discourse analysis and appraisal theory are the topics of the writing and information about them is important for scholars to know and share. Appreciation, then, is a dominant resource for evaluating or examining those topics of study. These findings confirm the findings of Hood (2004) who states that "the resultant rhetorical effect of the predominance of appreciation values is to make the text sound more appreciative than emotional and judgmental" (p. 127). Thus, the use of appreciation is an important resource that makes the introduction section more appreciative than emotional and judgmental.

Engagement is agreement and disagreement about expressing writers'/speakers' assumption/proposition toward the phenomena (Martin \& White, 2005, p. 95). It deals with the arguability of their proposition to engage dialogically with the interlocutors. Yang (2016) states that "engagement resources reflect writers/speakers' subjectivity or objectivity in the open dialogic space, 
and make the discourse more negotiable" (p. 1004). It is divided into monogloss and heterogloss. In this present study, the researchers focused on the analysis of heterogloss, including disclaim, proclaim, entertain, and attribute. The heteroglossic statements can be either contracting or expanding the proposition to negotiate the meaning. The expand makes allowances for dialogically alternative positions and voice actively, while contract makes allowances for an alternative, acting to challenge, fending off or restricting the scope of positions and voices.

In relation to the second domain of appraisal, engagement, the data analysis shows that the distribution of expand resources is the most dominant resource of engagement used by both the Indonesian and Chinese writers in their research article introductions. This finding is in line with the research findings of Mei and Allison (2003), Liu (2013), Yang (2016), Saptani (2017), Yuliana and Gandana (2018). The dominant use of expand resources indicates that the writers convey their proposition with external voices, to support the ideas and opinions in the introduction sections of their research articles. Jones (2011) stresses that the ethics of academic writing will guide students to respect and care for every reference that contributes to their writing. It makes their writing sound more objective, so their introduction sections also sound reasonable. Thus, by using expand resources, they attempt to strengthen their ideas and intention to create a clear position, by explaining the reasons why they chose the particular topics of their writing. Examples of expansive resources can be seen in Excerpts 3, 4 and 5. Excerpts 3 and 4 were written by Indonesian writers, while Excerpt 5 was written by a Chinese writer.

\section{Excerpt 3}

Dam and Volman (2004) point out that [ATTRIBUTE] critical thinking is the essence of thoughtful, democratic citizenship, and thus occupies in central position in education in the modern world.

In higher education, critical thinking is defined in terms of abilities or skills such as selection, evaluation, analysis, reflection, questioning, inference, and judgement $\underline{\text { (Tapper, }}$ 2004)[ATTRIBUTE](I8)

\section{Excerpt 4}

Compliments have been said to "grease the social wheels" and thus to serve as "social lubricants" (Wolfson, 1983, p.89)(ATTRIBUTE)(C7)

\section{Excerpt 5}

The discussion deals with poetic diction that may[ENTERTAIN] influence the whole(FORCE) message intended in both SL and TL poems(I5)

Excerpts 3, 4 and 5 show the appraising items of entertain and attribute as the dominant use of engagement resources in both the Indonesian and Chinese writers' introductions. It can be seen in Excerpt 3 that the writer provides external voices - Dan and Volman, and Tapper - to convey ideas from other sources that support and provide evidence for ideas and propositions about critical thinking. In addition, Excerpt 3 is in line with Excerpt 4 that also involves the attribute resources by representing an external source. In Excerpt 4, the writer takes Wolfson's idea that argues to the writer's idea relating to the topic. The appraising item of an attribute in Excerpt 4 is needed to build the writer's position so that the readers believe in the ideas or propositions that are being explained in the introduction section of the research article.

In Excerpt 5, the appraising item 'may' belongs to the expand resources in terms of entertain. According to Liu (2013), probability words such as 'may,' 'probably,' 'maybe,' and 'perhaps' are included in the entertain subsystem of engagement. Martin and White (2005) explain that entertain deals with "the proposition as grounded in its own contingent, individual subjectivity, the authorial voice represents the proposition as but one of a range of possible positions" (p. 98). This means that, in Excerpt 5, the appraising item 'may' represents the writer's individual subjectivity towards the discussion about the influence of poetic diction.

Both Indonesian and Chinese writers used external voices to support their arguments in explaining their reasons for choosing the topic in the research article. They also conveyed their individual subjectivity towards persuading the readers with the writers' viewpoint on the topic that is being discussed.

The third domain of appraisal resources is graduation. Graduation is concerned with the scaling of the meaning of the text in the context in which it is valued to the force and focus as the resources of graduation (Martin \& White, 2005). Martin and White (2005) explain that force "relies on the intensification and quantification that describe the degree of intensity and amount in the context" (p. 140). Focus relates to "the grading to core and marginal meaning in the context in which it lies on the resources of sharpen and soften scaling" (Martin \& Rose, 2003, p. 38).

In regard to the graduation analysis, both Indonesian and Chinese writers produced more force than focus. These findings are similar to those that have been reported in the studies conducted by Yang (2016) and Jalilifar and Hemmati (2016). The Indonesian and Chinese writers in this present study tended to emphasize their propositions through attitude and engagement by using intensification and quantification as subsystems of graduation. This shows how the Indonesian and Chinese writers intensify and quantify things or phenomena relevant to the topics in their introduction sections. The appraising items intensification and quantification are needed to show their emphasis on propositions and ideas through this resource, especially force resources. The examples of force resources are identified in Excerpts 6 and 7.

\section{Excerpt 6}

As students learning process happen at the university, the learning result is highly[FORCE] affected by the formality of the institute.

There is a phenomenon in English Department of UNNES where some[FORCE] students whose intelligence and 
behavior are praised as good or great by their lecturers and fellow colleagues are frequently [FORCE] selfexposed themselves with humor from internet which in most cases contains countervailing values compared to formal and positive(APPRECIATION) attitudes. (I4)

\section{Excerpt 7}

In the late 20th century, studies on the writing of English as a second language gradually[FORCE] developed, and, with its own theories, objects of study, research methods and research teams, it slowly[force] became an independent discipline that carried the clear study scope (Hyland, 2003, 2009; Kroll, 2003; Leki, Cumming, \& Silva, 2008; Silva \& Matsuda, 2012).

Generally speaking, Chinese second language writing research follows a multiple approach, with more[FORCE] scientific and practical studies and various [FORCE] research methods, and putting particular emphasis on writing teaching (see Figure 1). (C5)

In Excerpts 6 and 7, the appraising items 'highly,' 'frequently,' 'some,' 'gradually,' 'slowly,' 'more,' and 'various' are examples of force as the dominant resources of graduation. Those appraising items represent the writers' emphasis on ideas or propositions in the research article introduction. In Excerpt 6, the appraising items 'highly' and 'frequently' involve intensification to represent the intensity of the process in the context. It is evident that the writer of the research article is conveying his idea about a high degree of impact on learning results. Moreover, the appraising item 'some' is an example of quantification to convey a scaling of the number of subjects in the context. In this case, the writer uses 'some' to explain to readers that more than one student was involved in the context. The appraising item 'frequently' is indicated as intensification to express the level of quality in the context. This suggests that the case about the behaviour of students of UNNES often happens, to convince readers about the topic that is being discussed.

In Excerpt 7, the appraising item 'gradually' is to express the intensity of the process in the context. The writer describes a high level of intensity in the development of second language writing studies, while the appraising item 'slowly' explains the intensity of the process in carrying a clear study at a low degree. It indicates that the process of carrying a clear study does not occur in a quick way. In addition, the appraising item 'more' describes the intensity of quality of studies in the context. It means that the quality of studies becomes better than before, that is, more scientific and practical. The quantification belongs to the appraising item 'various' to describe the number of research methods in the context. It describes the variety of research methods that are conducted in Chinese studies.

In short, in terms of similarities in the use of appraisal resources, Indonesian and Chinese writers use more force in graduation in regard to quantification and intensification. The purpose of the use of force is to describe and explain the level of intensity and the number of things relating to the topic that is being discussed in the research articles introductions.

\section{Difference in the use of appraisal resources}

In terms of differences in the use of appraisal between the Indonesian and Chinese writers in this study, the Indonesian writers used more appraisal resources than the Chinese writers, except in relation to graduation resources. In other words, the Indonesian writers used more attitude and engagement than the Chinese writers did; whereas, the Chinese writers used more graduation resources. Although this was a small study, the differences between the two groups of writers raise some important considerations about why they exist. Because the study is based on the assumption that all of the writers were using English as a second or foreign language, it may be that some cultural factors are involved. For example, it might be because the Chinese writers try to maintain writer-reader relationships by avoiding explicit attitudinal evaluation of the work of others, as also found in Xiaoyu's study (2017).

This finding also confirms Yang's study (2016) that discovered that Chinese writers fell far behind American writers in the use of appraisal resources. This suggests that the Chinese writers have their own way to convey their ideas and arguments in the introduction sections, as found in the study conducted by Xie (2017) that Chinese writers "are generally able to manipulate the grading orientation in ways that are conducive to strengthening or weakening their evaluations when necessary" (p.17).

There are also other possibilities for explaining why the two groups of writers demonstrated different preferences for appraisal resources, including how the writers were taught to write in English. However, an explanation is beyond the scope of this study.

Despite the prominent difference that Indonesian writers in this present study use appraisal resources more frequently than the Chinese writers, the number of graduation resources used by Chinese writers is higher than Indonesian writers in the introduction sections of their research articles. This finding suggests that the Chinese writers emphasize their ideas and propositions more effectively than the Indonesian writers by using intensification and quantification. Liu (2013) asserts that the use of force is to build up persuasion; therefore, the Chinese writers tend to strengthen their voice in building the persuasiveness to the readers by using graduation resources.

To sum up, the findings have provided evidence of the way Indonesian and Chinese writers use the English language to present their propositions, ideas, and arguments in their research article introductions. They also convey the external voices and individual subjectivity to make their introduction sections more reasonable and objective to build up persuasiveness by expressing the scaling of intensification and quantification of their clauses. For teachers in English as a second or foreign language context, the findings of this study indicate that teachers need to be aware of potential differences between students from different countries in their use of appraisal resources. As will be explained in the Conclusions section, such awareness is 
important for considering the pedagogical implications of the findings.

\section{CONCLUSIONS}

Twenty introduction sections of research articles written by Indonesian and Chinese writers were examined to explore the use of appraisal resources and to discover the similarities and differences of the distribution of appraisal resources between the two groups of nonnative writers. The present study shows two prominent findings.

First, there is a noticeable similarity in overall use of appraisal resources, including attitude, engagement, and graduation. In attitude resources, Indonesian and Chinese writers mostly use appreciation in their research article introductions. This finding indicates that their writings are more appreciative than judgemental or emotional. Due to the higher use of appreciation, it makes their writings appreciate and evaluate things or phenomena relating to the topic that is being investigated. Moreover, Indonesian and Chinese writers predominantly have expand than contract resources in engagement to represent their ideas or propositions with external sources or voices to support arguments in their introduction sections. This means that the writers tend to strengthen their voices with acknowledgment of alternative positions. This makes the explanations in their writing sound more reasonable and objective.

Concerning the graduation resource, similar to the Indonesian writers, the Chinese writers produce a higher occurrence in force resource in their introduction sections. By using more of the force resource, their writing is able to achieve the purposes of aligning and persuading the readers. The use of force also indicates that the writers emphasize their choices of words to amplify attitude and engagement in intensifying and quantifying things or phenomena relating to the topic that is investigated to build up persuasion.

Second, the main difference in the use of appraisal resources between Indonesian and Chinese writers in their research article introductions is their use of graduation resources. There has been a similar amount of usage for the most dominant resources in overall appraisal resources involving attitude (appreciation), engagement (expand), and graduation (force). It is the use of graduation resources that shows a clear distinction between the Indonesian and Chinese writers. The Chinese writers are successful in producing more force than Indonesian writers. This indicates that the Chinese writers succeed to strengthen their arguments in order to persuade the readers through force resources.

In terms of the pedagogical implications gained for English writing instruction in English as second or foreign language contexts, this study provides some considerations for teachers about how writers from different cultural backgrounds can have different strengths and weaknesses in relation to the use of appraisal resources. However, because the findings are based on a small sample of written texts, the findings cannot be generalised to the broader population. Nevertheless, it is useful for teachers to know the types of differences that might exist and to plan to understand which appraisal resources their students can already use successfully.

Teaching should not be about a one-size-fits-all approach. Teachers need to be able to assess what their students are able to do and what they need to learn. Knowing that different students can use different appraisal resources could lead to some useful discussions with students about the work done by particular appraisal resources and how pieces of writing might be further strengthened. Another possibility might be the use of peer tutoring, where the students share their knowledge about appraisal resources.

\section{REFERENCES}

Chattergee, M. (2008). Textual engagement of a different kind? Bridging Discourses: ASFLA 2007 Online Proceedings (pp. 1-15). Retrieved from https://ro.uow.edu.au/cgi/viewcontent.cgi?referer= https://www.google.com/\&httpsredir=1\&article=1 302\&context=asdpapers

Farnia, M., \& Barati, S. (2017). Writing introduction sections of research articles in applied linguistics: Cross-linguistic study of native and non-native writers. Indonesian Journal of Applied Linguistics, 7(2), 486-494. doi: 10.17509/ijal.v7i2.8357

Hood, S. (2004). Appraising research: Taking a stance in academic writing (Unpublished doctoral dissertation). University of Technology Sydney, Australia.

Hyland, K. (2005). Stance and engagement: A model of interaction in academic discourse. Discourse Studies, 7(2), 173-192. doi: $10.1177 / 1461445605050365$

Hyland, K. (2009). Academic discourse: English in a global context. London, UK: Bloomsbury.

Jalilifar, A. R. (2010). Research article introductions: Sub-disciplinary variations in applied linguistics. Journal of Teaching Language Skills, 29(2), 29-55.

Jalilifar, A., \& Hemmati, A. (2013). Construction of evaluative meaning by Kurdish-speaking learners of English: A comparison of high- and low-graded argumentative essays. Issues in Language Teaching, 2(2), 7-84. doi: 10.22099/JTLS.2012.407

Jones, L. R. (2011). Academic integrity and academic dishonesty: A handbook about cheating and plagiarism. Melbourne, FL: Florida Institute of Technology.

Lee, S. H. (2006). The use of interpersonal resources in argumentative/persuasive essays by East-Asian ESL and Australian tertiary students. Unpublished doctoral dissertation, University of Sydney, Sydney, Australia.

Liu, X., \& Thompson, P. (2009). Attitude in students' argumentative writing: A contrastive perspective. In L. J. O’Brien \& D. S. Giannoni (Eds.), 
Language studies working papers (pp. 3-15). Reading, UK: University of Reading.

Liu, X. (2013). Evaluation in Chinese university EFL students' English argumentative writing: An appraisal study. Electronic Journal of Foreign Language Teaching, 10(1), 40-53.

Martin, J. R., \& Rose, D. (2003). Working with discourse: Meaning beyond the clause. London, UK: Continuum.

Martin, J. R., \& White, P. R. R. (2005). The language of evaluation: Appraisal in English. London, UK: Palgrave Macmillan.

Mei, W. S., \& Allison, D. (2003). Exploring appraisals in claims of student writers in argumentative essays. Prospect: An Australian journal of TESOL, 18(3), 71-91.

Rao, Z. (2013). Teaching English as a foreign language in China: Looking back and forward. English Today, 115(29), 34-39. doi: $10.1017 / \mathrm{S} 0266078413000291$

Saptani, D. A. (2017). The comparison of the use of appraisal resources in introductory section of final projects written by male and female students of Universitas Negeri Semarang. Unpublished master's thesis, Universitas Negeri Semarang, Semarang, Indonesia.

Stubbs, M. (1983). Discourse analysis: The sociolinguistics analysis of natural language. Chicago, IL: University of Chicago Press.
Thornbury, S. (2005). Beyond the sentence: Introducing discourse analysis. London, UK: Macmillan Education.

White, P. R. R. (2015). Appraisal theory. In K. Tracy, C. Ilie, \& T. Sandel (Eds.), The international encyclopedia of language and social interaction (Vol. 1, pp. 54-158). Hoboken, New Jersey: John Wiley \& Sons.

Widdowson, H. G. (2004). Text, context, pretext: Critical issues in discourse analysis. Malden, MA: Wiley-Blackwell.

Xiaoyu, X. (2017). An analysis of stance and voice in research articles across Chinese and British cultures, using the appraisal framework (Doctoral dissertation). Coventry University, England, UK.

Xie, J. (2017). Evaluation in moves: An integrated analysis of Chinese MA thesis literature reviews. English Language Teaching, 10(3), 1-20.

Xinghua, L., \& Thompson, P. (2009). Attitude in students' argumentative writing: A contrastive perspective. Language Studies Working Papers, l(1), 3-15.

Yang, Y. (2016). Appraisal resources in Chinese college students' English argumentative writing. Journal of Language Teaching and Research, 7(5), 10021013.

Yuliana, D. \& Gandana, I. S. S. (2017). Writers' voice and engagement strategies in students' analytical exposition texts. International Journal of Applied Linguistics, 7(3), 613-620. doi: 10.17509/ijal.v7i3.9812 